\title{
SACHET DRINKING WATER IN ACCRA: THE POTENTIAL THREATS OF TRANSMISSION OF ENTERIC PATHOGENIC PROTOZOAN ORGANISMS
}

\author{
G. KWAKYE-NUAKO, P.B. BORKETEY, I. MENSAH-ATTIPOE, ${ }^{1}$ R.H. ASMAH \\ And *P.F. AYEH-KUMI \\ Department of Microbiology, University of Ghana Medical School, P. O. Box 4236, Accra, Ghana \\ and ${ }^{1}$ Department of Medical Laboratory Sciences, School of Allied Health Sciences, Korle-Bu, Ghana
}

\section{SUMMARY}

Background: The recent introduction of sachet water to consumers was to provide safe, hygienic and affordable instant drinking water to the public. Although this is a laudable idea current trends seem to suggest that sachet drinking water could be a route of transmission of enteric pathogens.

Objective: To assess the safety of sachet drinking water.

Materials and Methods: Twenty seven different brands of $500 \mathrm{ml}$ sachet water samples randomly selected and purchased from various vendors in Accra were subjected to microscopic examinations to determine the presence of parasitic protozoa. The study was carried out between January and May 2005.

Results: Seventy-seven percent of the samples contained infective stages of pathogenic parasitic organisms. Common pathogens identified include, Microsporidia sp 14/27 (51.2\%), Cryptosporidium parvum 17/27 (63.0\%), Cyclospora cayetenensis 16/27 (59.3\%), Sarcocystis sp. 18/27 (66.7\%). Rotifers 5/27 (18.5\%), and Charcoat Leyden crystals $12 / 27(44.4 \%)$. Ninety-three percent of the samples contained unidentified impurities/artifacts. $29.6 \%$ of the samples contained at least one type of parasite, $14.8 \%$ contained at least 2 types of parasites, $25.9 \%$ contained at least three types of parasites, while $29.6 \%$ contained four types of parasites.

Conclusion: The study indicated the presence of contaminants of feacal and zoonotic origin in some of the sachet water examined. This has grim public health implications as the organisms identified can cause water related diseases which have serious complications in children and adults particularly immunocompromised individuals. Sachet water should be constantly monitored for its microbial quality.
Keywords: Sachet drinking water, protozoan parasites, Ghana, food safety

\section{INTRODUCTION}

The intake of unwholesome water could have devastating effects on our health as unsafe drinking water is a key determinant of many microbial diseases with serious complications in immunocompetent and immunocompromised individuals ${ }^{1}$. The introduction of sachet water in Ghana was to provide safe, hygienic and affordable instant drinking water to the public and to curb the magnitude of water related infections in the country.

Earlier investigations conducted on the safety of drinking water in Ghana has shown that bottled water on the Ghanaian market is of good microbiological quality while the quality of some factorybagged sachet and hand-filled/hand-tied polythene-bagged drinking water was noted to be doubtful ${ }^{2}$. This observation was based on studies carried out on water samples to ascertain the presence of heterotrophic bacteria, indicators of faecal contamination (total coliforms, faecal coliforms and enterococci) and for lead, manganese and iron. Lack of information on pathogenic parasitic organisms associated with drinking water on our markets creates some uncertainties in our understanding of the overall quality of drinking water on our markets. To clarify this, there is an urgent need for the determination of protozoan and helminthic organisms associated with drinking water in our communities.

Protozoan organisms are ubiquitous and could be found in various systems including water bodies. Common examples of parasitic protozoa often encountered in water include Cryptosporiduim parvum, Giardia lamblia, Entamoeba histolytica, Microsporidia sp. and Cyclospora cayetenensis ${ }^{1}$,

${ }^{3,4}$. The presence of these organisms in sources of

* Author for correspondence payehkumi@yahoo.com 
drinking water is partly due to four reasons: Firstly, these organisms are indigenous pathogens found in most domestic animals; secondly, the degree of environmental contamination with their infective stages; thirdly, their resistance to water purification processes and finally unhygienic handling of drinking water ${ }^{5,6}$.

C. parvum has been acknowledged as a human pathogen since $1976^{7}$ and is noted to be associated with various forms of waterborne outbreaks among several categories of people ${ }^{8}$. Potential sources of infection include the ingestion of contaminated food and water and the use of recreational facilities $^{6,9}$. Although studies indicate that the median infectious dose is about 132 oocysts $^{10}$, the ingestion of only one oocyst is noted to have caused disease in people ${ }^{11}$. G. lamblia, is a well known cause of diarrhea ${ }^{4}$ and infection is acquired via person to person contact and waterborne sources $^{1,12}$. The ingestion of as few as 10 cysts is enough to cause infection in humans ${ }^{13}$.

E. histolytica is a major cause of morbidity and mortality worldwide ${ }^{14}$ and contaminated water is a prime source of infection in many areas ${ }^{15}$. C. cayetenensis is a newly identified coccidian protozoan parasite that has also been found to be associated with drinking water ${ }^{1,16}$. The link between Microsporidia infections and water contact has been reported in various locations and there are suggestions that their transmission could be through drinking water ${ }^{17}$.

The introduction of sachet (factory bagged) water on our markets was done in a bid to curb the public health implications of consuming unwholesome water in Ghana. The objective of this study was to determine if sachet drinking water on our markets contain any pathogenic parasitic protozoan organisms.

\section{MATERIALS AND METHODS}

Twenty seven (27) brands of $500 \mathrm{ml}$ sachet water samples (all produced in Accra, Ghana) were purchased from roadside and market vendors in Accra. Each sample was vigorously shaken and dispensed into ten $50 \mathrm{ml}$ sterile test tubes. The test tubes and their contents were centrifuged at 2000 rpm for 5 minutes. The contents of each set of ten test tubes were pooled together after the supernatant fluid has been discarded, and re-spun under the same conditions. The supernatant fluid was again discarded, and the remaining sediments were subjected to microscopic examination.

\section{Wet Mounts}

A drop of suspended sediments (in saline) was placed on a slide and mixed with a drop of iodine solution using an applicator stick. The mixture was covered with a cover slip and examined microscopically using X 10 and X 40 objective lenses ${ }^{18}$.

\section{Trichrome stain technique}

A drop of each sediment was placed on a labelled slide and spread in a thin uniform smear using an applicator stick. Each slide fixed in Schaudins's fixative for 30 minutes. The slides were then transferred once into iodine-alcohol solution for 1 minute, then twice into $70 \%$ ethanol for 1 minute and stained with trichrome stain for 8 minutes and destained with acetic acid-alcohol solution for 5 seconds. The slides were dipped twice in 95\% ethanol for 2 seconds and finally into absolute ethanol for 1 minute and transferred into xylene for 2 minutes. A mounting medium was placed on the slides and a cover slip was applied. Slides were examined as for the wet mounts ${ }^{19}$.

\section{Modified Zielhl-Neelsen technique}

Thin and uniform smears were prepared from sediments as was done for the trichrome stain technique and fixed in methanol for 2 minutes. The slides were stained with cold carbol-fuchsin for 5 minutes and differentiated in $1 \%$ hydrochloric acid-ethanol for 5 minutes. Slides were rinsed under tap-water for 5 minutes and counter-stained with $0.25 \%$ malachite green. Slides were again rinsed in tap-water for 5 minutes and drained to dry. Slides were examined using high-power objective lens ${ }^{20}$.

\section{RESULTS}

Parasitic organisms were identified in 21/27 $(77.8 \%)$ of the samples (Table 1) while 26/27 $(96.3 \%)$ of the samples contained non-pathogenic materials and various artefacts (Table 2). Infective stages of four common protozoan pathogens were identified (Figure 1) in the following proportions; Microsporidia sp 14/27 (51.2\%), Cryptosporidium parvum 17/27 (63.0\%), Cyclospora cayetenensis 16/27 (59.3\%), Sarcocystis spp. 18/27 (66.7\%). Rotifers 5/27 (18.5\%), Charcoat Leyden crystals $12 / 27(44.4 \%)$ and unidentified impurities and artifacts $(96.3 \%)$ in the various water samples (Figure 2).

The parasitic load found in the various samples differed markedly. Over twenty nine percent $(29.6 \%)$ of the samples examined contained at least one type of parasite, $14.8 \%$ contained at least two types of parasites, $25.9 \%$ contained at least 
three types of parasites, while $29.6 \%$ contained four types of parasites.

Table 1 Number of pathogenic organisms per field per $10 \mu \mathrm{l}$ of deposits/sachet water sample

\begin{tabular}{cccccc}
\hline \multicolumn{5}{c}{ Pathogenic Organism (No/Field/10 $\boldsymbol{\mu l}$ ) under } \\
Code & $\begin{array}{c}\text { Microsp } \\
\text { oridia }\end{array}$ & $\begin{array}{c}\text { C.cayet } \\
\text { enensis }\end{array}$ & $\begin{array}{c}\text { C. } \\
\text { parvum }\end{array}$ & $\begin{array}{c}\text { Sarco } \\
\text { cystis }\end{array}$ & Total \\
\hline 002 & 30 & 2 & 2 & - & 34 \\
003 & 50 & 3 & 20 & 2 & 75 \\
004 & 20 & 10 & - & 10 & 40 \\
005 & 50 & 1 & - & 5 & 56 \\
$\mathbf{0 0 6}$ & 30 & 5 & - & 2 & 37 \\
007 & 50 & 1 & - & - & 51 \\
008 & 20 & 3 & 3 & 2 & 28 \\
$\mathbf{0 0 9}$ & 20 & - & 3 & - & 23 \\
$\mathbf{0 1 0}$ & 20 & 3 & 3 & 3 & 29 \\
$\mathbf{0 1 1}$ & 10 & 2 & 2 & 2 & 16 \\
$\mathbf{0 1 4}$ & 8 & 3 & 2 & 4 & 17 \\
$\mathbf{0 1 5}$ & - & - & - & 2 & 2 \\
$\mathbf{0 1 6}$ & - & - & 1 & 2 & 3 \\
$\mathbf{0 1 7}$ & - & 2 & 1 & 10 & 13 \\
$\mathbf{0 1 8}$ & - & 2 & 2 & 2 & 6 \\
$\mathbf{0 1 9}$ & - & - & - & 2 & 2 \\
$\mathbf{0 2 0}$ & 30 & 1 & 1 & 4 & 36 \\
$\mathbf{0 2 1}$ & 50 & 1 & 1 & 1 & 53 \\
$\mathbf{0 2 2}$ & - & - & 1 & 2 & 3 \\
$\mathbf{0 2 5}$ & 50 & 1 & 2 & 1 & 54 \\
$\mathbf{0 2 6}$ & - & 1 & 10 & 2 & 13 \\
\hline$*$ Code numbers shown in bold characters indicate samples & with Ghana \\
Standards Board Symbol & & & & \\
& & & & &
\end{tabular}

a.
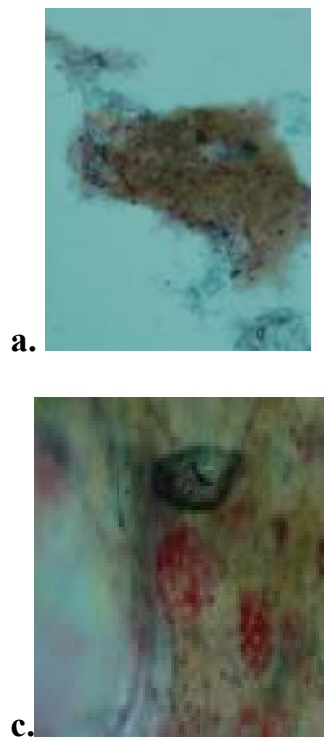

b.
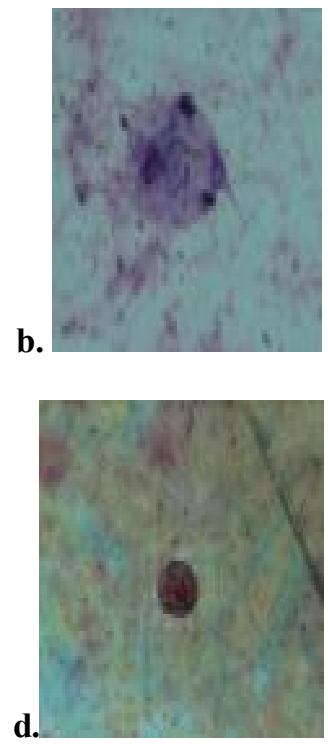

Figure 1 Some of the organisms found in the water samples. a) A mixture of artifacts and spores of Microsporidia. b) Rotifer. c) Cyclospora spp and d) Cryptosporidium spp. A, C and D are stained with $\mathrm{ZN}$ stain while B is stained with Trichrome stain. Magnification $\mathrm{x} 100$.

Vital information required for the protection of consumers was lacking on some of the water sachets. None of the brands had batch numbers and all the packs had no records of the dates of manufacture. Contact addresses were however indicated on all the packs and $23 / 27(85.2 \%)$ of the packs had the expiry dates printed on the sachets.

Table 2 No. of non-pathogenic organism/particles per field per $10 \mu \mathrm{l}$ of deposits/sachet water sample

\begin{tabular}{|c|c|c|c|c|}
\hline \multirow[b]{2}{*}{ Code } & \multicolumn{4}{|c|}{ Particle $($ No/Field/10 $\mu l)$ under x 100} \\
\hline & $\begin{array}{l}\text { Ro- } \\
\text { tifer }\end{array}$ & $\begin{array}{c}\text { Charcoat Ley- } \\
\text { den Crystals }\end{array}$ & $\begin{array}{l}\text { Arti- } \\
\text { fact }\end{array}$ & Total \\
\hline 001 & 3 & - & 1 & 4 \\
\hline 002 & 2 & 20 & 3 & 25 \\
\hline 003 & - & - & 6 & 6 \\
\hline 004 & - & 10 & 2 & 12 \\
\hline 005 & - & 5 & 10 & 15 \\
\hline 006 & - & 1 & 4 & 5 \\
\hline 007 & - & 20 & 6 & 26 \\
\hline 008 & - & 2 & 5 & 7 \\
\hline 009 & - & - & 4 & 4 \\
\hline 010 & - & - & 5 & 5 \\
\hline 011 & 5 & 10 & 2 & 17 \\
\hline 012 & - & - & 3 & 3 \\
\hline 013 & - & - & 1 & 1 \\
\hline 014 & - & - & 5 & 5 \\
\hline 015 & 1 & - & 3 & 3 \\
\hline 016 & 1 & - & 4 & 5 \\
\hline 017 & - & 1 & 50 & 51 \\
\hline 018 & - & - & 8 & 8 \\
\hline 019 & - & - & 2 & 2 \\
\hline 020 & - & 2 & 6 & 8 \\
\hline 021 & - & 6 & 10 & 16 \\
\hline 022 & - & 2 & 4 & 6 \\
\hline 023 & - & - & 2 & 2 \\
\hline 024 & - & - & - & 0 \\
\hline 025 & - & - & 6 & 6 \\
\hline 026 & - & 1 & 2 & 3 \\
\hline 027 & - & - & 1 & 1 \\
\hline
\end{tabular}

Standards Board Symbol

The most predominant organism identified was Microsporidia sp. which showed up in 14/27 $(52 \%)$ of the samples. High numbers of small resistant spores of this pathogen were encountered in the water samples.

Most of the samples that were noted to be contaminated with Microsporidia sp. were also found to contain Cyclospora sp. while samples that were contaminated with Cryptosporidium mostly contained Sarcocystis as a second common contaminant (Table 1). Over five percent of the samples 
were found to be very slimy and had objectionable odour.

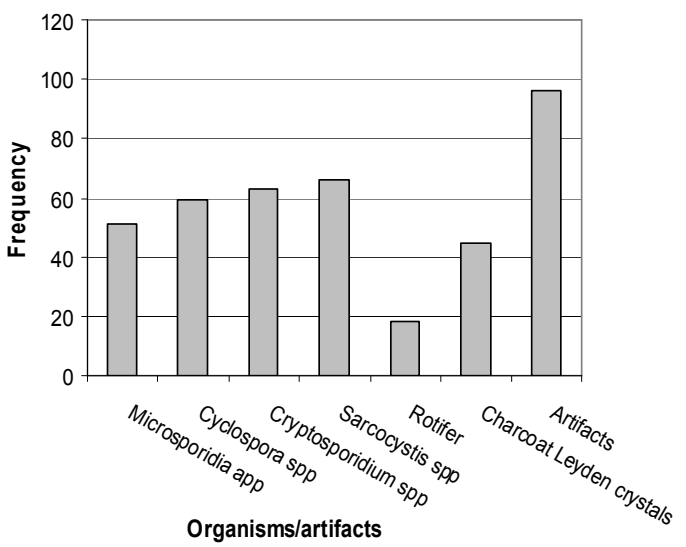

Figure 2 Frequency of organisms/artifacts in water samples

\section{DISCUSSION}

The prevalence of water related diseases in developing countries is determined by the quality of their drinking water. The safety of drinking water in poor and deprived communities has in the last decade been in jeopardy as a result of wanton introduction of refuse and sewage into sources of water supply. The introduction of the sachet drinking water on the Ghanaian market was a laudable idea but studies suggest that this innovative idea is not risk free ${ }^{2}$.

The objective of this study was to assess the safety of sachet drinking water for human consumption and the possibility that it could serve as a route of transmission of protozoan parasites has been confirmed. The study has revealed the occurrence of high proportions of pathogenic and nonpathogenic protozoan organisms in some of the sachet water on our markets. Four protozoan pathogens mainly of feacal and zoonotic origin were identified; Microsporidia sp., Cryptosporidium parvum, Cyclospora sp., Sarcocystis sp. Over 55\% of the samples tested contained unacceptably high numbers of minute resistant spores of Microsporidia sp. This observation suggests the existence of a significant level of contaminants in some of our sachet water. The result of this study support the findings of a similar study carried out in Kumasi to determine the microbial quality of water on the streets $^{2}$.

Several factors potentially accounted for this observation, notable among these are; improper processing and purification procedures, unhygienic handling after production, the small size of the pathogens which enable them to escape filtration and the resistance of these pathogens to physical water treatment agents and disinfectants ${ }^{21}$. The presence of live Rotifers commonly found in ponds, was a strong indication of the presence of a high level of organic material enough to support life and other biological activities of these organisms. This could explain why some of the samples were noted to be slimy with objectionable odour.

The organisms encountered in this study are potential pathogens associated with water related diarrhoea outbreaks in healthy people with devastating presentations in the immunocompromised individuals ${ }^{22}$. Characteristics of these organisms include; the low infective dose (1-10 oocysts), the infectious nature of the various oocyst of these organisms immediately after excretion in faeces, the stability of these oocysts in our environment and the rapid rate of environmental dispersal ${ }^{23}$. All these factors affect the dynamics of the epidemiology of these infections in our environment.

In view of the prevalence of HIV infection in our communities coupled with the devastating consequences of these infections among immunocompromised individuals, it is important to raise the general awareness of the public over the need for safe drinking water ${ }^{24}$. This study gives belief to the fact that the magnitude of water related parasitic human diarrhea disease due to the intake of contaminated drinking water in our communities is undoubtedly underestimated. Again from this study, it has become clear to estimate the extent to which contaminated drinking water contributes to the overall disease burden of the Ghanaian population. More attention should be focused on the identification of water related protozoan pathogens in our drinking water since markers validated for bacterial contamination are not appropriate for the detection of these potential contaminants. Infections caused by these parasitic organisms should critically be considered potential waterborne diseases in our environment.

\section{CONCLUSION}

In conclusion, this study shows that some sachet water on our markets could serve as possible routes of transmission of protozoan parasites.

Like other countries, we need to implement measures and regulations that would critically minimize and control the spread of waterborne diseases ${ }^{25,26}$. Epidemiological and risk assessment approaches will undoubtedly boost our understanding of the 
occurrence, survival and transport of these organisms. Regardless of these measures, the possibility for contaminated water to cause significant diseases in our communities still remains due to problems associated with water purification and distribution.

While standards used for the assessment of sachet water seems to be silent on the limits of protozoa in sachet drinking water ${ }^{25}$, we wish to recommend further investigations on sachet water to assess water quality at the following important levels: before production, after production at the factories and at the point of consumption in order to ensure their quality and safety.

\section{ACKNOWLEDGEMENT}

The authors wish to express their sincere gratitude to Prof. Mercy J Newman, and Prof. K TwumDanso, all of the Microbiology Department, UGMS for their assistance and useful suggestions. We also wish to thank Dr. R. Kumorji of the Department of Pathology, UGMS for technical assistance.

\section{REFERENCES}

1. Steiner TS, Thielman NM, Guerrant RL. Protozoal Agent: What Are the Dangers for Public Water Supply? Ann Rev Med 1997; 48: 329-340.

2. Obiri-Danso K, Okore-Hanson A, Jones K. The Microbiological quality of drinking water sold on the streets of Kumasi, Ghana. Lttr Appl Microbiol 2003; 37(4): 334.

3. de la Maza LM, Pezzlo MT, Baron ET. Coloured Atlas of Diagnostic Microbiology, Walsworth Press Inc., Marceline, Missouri 1997; 175.

4. KonemanWE, Allen SD, Janda WM, Schreckenberger PC, Winn WC. Jr. Diagnostic Microbiology, 4th Edition, J. B. Lillincott Company, Philadelphia. 1992; 907-909.

5. Meisel JL, Perea DR, Meligro C, et al. Overwhelming watery diarrhoea associated with Cryptosporidium in immunocompromised patient. Gastroenterol 1976; 70: 1156-1160.

6. LeChevallier MW, Norton WD, Lee RG. Occurrence of Giardia and Cryptosporidium spp. in surface water supplies. Appl Environ Microbiol 1991; 57(9): 2610-2616.
7. Kramer MH, Herwaldt BL, Craun GF, et al. Surveillance for waterborne disease - United States, 1993-1994. MMWT CDC Surveill Summ 1996; 45(SS-1): 1-33.

8. MacKenzie WR, Hoxie NJ, Proctor ME, et al. A massive outbreak in Milwaukee of Cryptosporidium infection transmitted through the public water supply. $N$ Engl J Med 1994; 331: 161-167.

9. Roach PD, Olson ME, Whitley G, Wallis PM. Waterborne Giardia cysts and Cryptosporidium oocysts in the Yukon, Canada. Appl Environ Microbiol 1993; 59(1): 67-73.

10. Owens JH, Miltner RJ, Scaefer FW, Rice EW. Pilot-scale ozone inactivation of Cryptosporidium. J Eukaryot Microbiol 1994; 41(5): 56$57 \mathrm{~S}$.

11. DuPont HL, Chapell CL, Sterling CR, et al. The infectivity of Cryptosporidium parvum in health volunteers. $N$ Engl J Med 1995; 332: 855-859.

12. Rendtorff RC. The experimental transmission of Giardia lamblia among volunteer subjects. In Waterborne Transmission of Giardiasis. Cincinnati: Environtal Protection Agency. 1979; 1-10

13. Agnew DG, Lima AA, Newman RD, et al. Cryptosporidiosis in northeastern Brazilian children. In Intersci Conf Antimicrob Agen Chemother, Orlando, (Abstr.) 1994; 5-8: 270

14. Petri WA, Jr. Recent advances in amoebiasis. Crit Rev Clin Lab Sci 1996; 33(1): 1-37.

15. Wurtz R. Cyclospora: a newly identified intestinal pathogen of humans. Clin Infect Dis 1994; 18: 620-23.

16. Ortega YR, Sterling CR, Gilman RH, et al. Cyclospora sp-a new protozoan pathogen of humans. N Engl J Med 1993; 328: 1308-1312.

17. Hoge CW, Shlim DR, Rajah R, et al. Epidemiology of diarrhoeal illness associated with coccidian-like organism among travelers and foreign residents in Nepal. Lancet 1993; 341: 1175-1179. 
18. World Health Organization. Basic laboratory methods in medical parasitology. Macmillan/Clays England. 1991; 11-12: 17-20.

19. Kaplan RL. Microscopic examination of faecal specimens: Permanent stained smears (Trichrome). In Clinical Microbiology Procedures Handbook. Vol. 2. Edited by Isenberg H. D. American Society of Microbiologists, Washington. 1992; 7.3.6.1

20. Shimizu RY. Special stains for Coccidia and Cynobacterium-like Bodies: Modified ZiehlNeelsen Aci-d Fast Stain (Hot). In Clinical Microbiology Procedures Handbook. Vol. 2. Edited by Isenberg H. D. American Society of Microbiologists, Washington. 1992; 7.4.2.1

21. Cotte L, Rabodonirima M, Chapuis F, Bissuel F, et al. Water outbreak of Intestinal Microsporidiosis in persons with or without Human immunodeficiency virus infection. J. Infect. Dis. 1999; 180: 2003-2008.
22. Kartalija $M$ and Sande MA. Diarrhea and AIDS in the era of Highly Active Antiretroviral Therapy. Clin Infect Dis 1999; 28: 701705.

23. Nime FA, Burek JD, Page DL, Holscher MA, Yardley JH. Acute enterocolitis in a human being infected with protozoan Cryptosporidium. Gastroenterol 1976; 70: 592-598

24. Cimerman S, Cimerman B, Lewi DS Enteric parasites and AIDS. Sao Paulo Med J 117: 266-273.

25. Current WL, Garcia LS. Cryptosporidiosis. Clin Microbiol Rev 1991; 4: 325-358.

26. Tzipori S, Angus KW, Gray EW, Campbell I, Allen F. Vomiting and diarrhea associated with Cryptosporidium infection. $N$ Engl J Med 1980; 303: 818 . 